\title{
Electrohypersensitivity: State-of-the-Art of a Functional Impairment
}

\author{
OLLE JOHANSSON
}

Department of Neuroscience, Karolinska Institute, Stockholm, Sweden

\begin{abstract}
Recently, a new category of persons, claiming to suffer from exposure to electromagnetic fields, has been described in the literature. In Sweden, electrohypersensitivity (EHS) is an officially fully recognized functional impairment (i.e., it is not regarded as a disease). Survey studies show that somewhere between 230,000290,000 Swedish men and women report a variety of symptoms when being in contact with electromagnetic field (EMF) sources. The aim of our studies has been to investigate possible alterations, in the cellular and neuronal systems of these persons' skin. As controls, age-and sex-matched persons, without any subjective or clinical symptoms or dermatological history, served. Immunohistochemistry using antisera to the previously characterized marker substances of interest has been utilized. In summary, it is evident from our preliminary data that various alterations are present in the electrohypersensitive persons' skin. In view of recent epidemiological studies, pointing to a correlation between long-term exposure from power-frequent magnetic fields or microwaves and cancer, our data ought to be taken seriously and further analyzed.
\end{abstract}

Keywords Dermatoscience; Electrohypersensitivity; Impairment; Immunohistochemistry; Neuroscience.

An ever increasing number of studies has clearly shown various biological effects at the cellular level of electromagnetic fields, including power-frequent and radiofrequent ones as well as microwaves. Such electromagnetic fields are present in your everyday life, at the workplace, in your home, and at places of leisure.

Recently, a new category of persons with a functional impairment (electrohypersensitivity; EHS) has been described in the literature, namely those that claim to suffer from subjective and objective skin- and mucosa-related symptoms, such as itch, smarting, pain, heat sensation, redness, papules, pustles, etc., after exposure to visual display terminals (VDTs), mobile phones, DECT telephones, as well as other

Address correspondence to Olle Johansson, Department of Neuroscience, Karolinska Institute, The Experimental Dermatology Unit, 17177 Stockholm, Sweden; E-mail: olle.johansson@.ki.se 
electromagnetic devices. Frequently, symptoms from internal organ systems, such as the heart and the central nervous system, are also encountered.

Persons claiming such adverse skin reactions after having been exposed to computer screens or mobile phones very well could be reacting in a highly specific way and with a completely correct avoidance reaction, especially if the provocative agent was radiation and/or chemical emissions-just as you would do if you had been exposed to, e.g., sun rays, X-rays, radioactivity, or chemical odors. The working hypothesis, thus, early became that they react in a cellularly correct way to the electromagnetic radiation, maybe in concert with chemical emissions such as plastic components, flame retardants, etc., something later focused upon by professor Denis L. Henshaw and his collaborators at the Bristol University (cf. Fews et al., 1999a,b). This is also covered in great depth by Gunni Nordström in her latest book (2004).

Very soon, however, from different clinical colleagues, and in parallel to the above, a large number of other 'explanations' became fashionable, e.g., that the persons claiming electrohypersensitivity were only imagining this, or they were suffering from post-menopausal psychological abberations, or they were old, or having a short school education, or were the victims of classical Pavlovian conditioning, or a journalist-driven mass media psychosis. Strangely enough, most of the, often self-made, 'experts' who proposed these explanations had themselves never met anyone claiming electrohypersensitivity and these 'experts' had never done any investigations of the proposed explanatory models.

The aim of our own studies has been to investigate possible alterations, in the cellular and neuronal systems of these persons' skin. As controls, age- and sexmatched persons, without any subjective or clinical symptoms or dermatological history, have served. Immunohistochemistry using antisera to the previously characterized marker substances of interest has been utilized. Among many discoveries, the following may be mentioned.

We have investigated the presence of intraepidermal nerve fibers in normal human skin from healthy volunteers using the new marker PGP 9.5 (Hilliges et al., 1995; Johansson et al., 1999; Wang et al., 1990). The intraepidermal nerve fibers are found as close as $20-40 \mu \mathrm{m}$ from the surface, which makes it highly possible that weak electromagnetic fields may affect them.

In facial skin samples of electrohypersensitive persons, the most common finding is a profound increase of mast cells. Nowadays we do not only use histamine, but also other mast cell markers such as chymase and tryptase, but the pattern is still the same as reported previously for other electrohypersensitive persons (Johansson and Liu, 1995). From these studies, it is clear that the number of mast cells in the upper dermis is increased in the electrohypersensitivity group. A different pattern of mast cell distribution also occurred in the electrohypersensitivity group, namely, the normally empty zone between the dermo-epidermal junction and mid-to-upper dermis disappeared in the electrohypersensitivity group and, instead, this zone had a high density of mast cell infiltration. These cells also seemed to have a tendency to migrate towards the epidermis (=epidermiotrophism) and many of them emptied their granular content (=degranulation) in the dermal papillary layer. Furthermore, more degranulated mast cells could be seen in the dermal reticular layer in the electrohypersensitivity group, especially in those cases which had the mast cell epidermiotrophism phenomenon described above. Finally, in the electrohypersensitivity group, the cytoplasmic granules were more densely 
distributed and more strongly stained than in the control group, and, generally, the size of the infiltrating mast cells was found to be larger in the electrohypersensitivity group as well. It should be noted that increases of similar nature later on were demonstrated in an experimental situation employing normal healthy volunteers in front of visual display units, including ordinary household television sets (Johansson et al., 2001).

In one of the early papers (Johansson et al., 1994), we made a sensational finding when we exposed two electrically sensitive individuals to a TV monitor. When we looked at their skin under a microscope, we found something that surprised us. In this article, we used an open-field provocation, in front of an ordinary TV set, of persons regarding themselves as suffering from skin problems due to work at video display terminals. Employing immunohistochemistry, in combination with a wide range of antisera directed towards cellular and neurochemical markers, we were able to show a high-to-very high number of somatostatin-immunoreactive dendritic cells as well as histamine-positive mast cells in skin biopsies from the anterior neck taken before the start of the provocation. At the end of the provocation the number of mast cells was unchanged, however, the somatostatin-positive cells had seemingly disappeared. The reason for this latter finding is discussed in terms of loss of immunoreactivity, increase of breakdown, etc. The high number of mast cells present may explain the clinical symptoms of itch, pain, edema, and erythema.

We have compared facial skin from electrohypersensitive persons with corresponding material from normal healthy volunteers (Johansson et al., 1996). The aim of the study was to evaluate possible markers to be used for future doubleblind or blind provocation investigations. Differences were found for the biological markers calcitonin gene-related peptide (CGRP), somatostatin (SOM), vasoactive intestinal polypeptide (VIP), peptide histidine isoleucine amide (PHI), neuropeptide tyrosine (NPY), protein S-100 (S-100), neuron-specific enolase (NSE), protein gene product (PGP) 9.5, and phenylethanolamine N-methyltransferase (PNMT). The overall impression in the blind-coded material was such that it turned out easy to blindly separate the two groups from each other. However, no single marker was $100 \%$ able to pin-point the difference, although some were quite powerful in doing so (CGRP, SOM, S-100). In our ongoing investigations, we have also found alterations of the Merkel cell number in the facial skin of electrohypersensitive persons (Yoshimura et al., 2006). However, it has to be pointed out that we cannot, based upon those results, draw any definitive conclusions about the cause of the changes observed. Blind or double-blind provocations in a controlled environment (Johansson et al., 2001) are necessary to elucidate the underlying causes for the changes reported in this particular investigation.

I and my collaborator, Dr. Shabnam Gangi, in two papers of theoretical nature (Gangi and Johansson, 1997, 2000), have put forward a model for how mast cells and substances secreted from them (e.g., histamine, heparin, and serotonin) could explain sensitivity to electromagnetic fields. The model bounces off from known facts in the fields of UV- and ionizing irradiation-related damages, and uses all the new papers dealing with alterations seen after, e.g., power-frequent or microwave electromagnetic fields, to propose a simple summarizing model for how we can understand the phenomenon of electrohypersensitivity.

In the first paper (Gangi and Johansson, 1997), we describe the fact that an increasing number of persons say that they get cutaneous problems as well 
as symptoms from certain internal organs, such as the central nervous system and the heart, when being close to electric equipment. A major group of these persons are the users of video display terminals, who claim to have subjective and objective skin- and mucosa-related symptoms, such as pain, itch, heat sensation, erythema, papules, and pustules. The central nervous system-derived symptoms are, e.g., dizziness, tiredness, and headache. Erythema, itch, heat sensation, edema, and pain are also common symptoms of sunburn (UV dermatitis). Alterations have been observed in cell populations of the skin of electrohypersensitive persons similar to those observed in the skin damaged due to ultraviolet light or ionizing radiation. In electrohypersensitive persons a much higher number of mast cells have been observed. It is known that UVB irradiation induces mast cell degranulation and release of TNF-alpha. The high number of mast cells present in the electrohypersensitivity group and the possible release of specific substances, such as histamine, may explain their clinical symptoms of itch, pain, edema, and erythema. The most remarkable change among cutaneous cells, after exposure with the above-mentioned irradiation sources, is the disappearance of the Langerhans' cells. This change has also been observed in electrohypersensitive persons, again pointing to a common cellular and molecular basis. The results of this literature study demonstrate that highly similar changes exist in the skin of electrohypersensitive persons, as regards the clinical manifestations as well as alterations in the cell populations, and in skin damaged by ultraviolet light or ionizing radiation.

In the second publication (Gangi and Johansson, 2000), the relationship between exposure to electromagnetic fields and human health is even more in focus. This is mainly because of the rapidly increasing use of such electromagnetic fields within our modern society. Exposure to electromagnetic fields has been linked to different cancer forms, e.g., leukemia, brain tumours, neurological diseases, such as Alzheimer's disease, asthma, and allergy, and to the phenomenon of electrohypersensitivity/screen dermatitis. There is an increasing number of reports about cutaneous problems as well as symptoms from internal organs, such as the heart, in people exposed to video display terminals. These people suffer from subjective and objective skin and mucosa-related symptoms, such as itch, heat sensation, pain, erythema, papules, and pustules (cf. above). In severe cases, people cannot, for instance, use video display terminals or artificial light at all, or be close to mobile telephones. Mast cells, when activated, release a spectrum of mediators, among them histamine, which is involved in a variety of biological effects with clinical relevance, e.g., allergic hypersensitivity, itch, edema, local erythema, and many types of dermatoses. From the results of recent studies, it is clear that electromagnetic fields affect the mast cell, and also the dendritic cell, population, and may degranulate these cells. The release of inflammatory substances, such as histamine, from mast cells in the skin results in a local erythema, edema, and sensation of itch and pain, and the release of somatostatin from the dendritic cells may give rise to subjective sensations of ongoing inflammation and sensitivity to ordinary light. These are, as mentioned, the common symptoms reported from persons suffering from electrohypersensitivity/screen dermatitis. Mast cells are also present in the heart tissue and their localization is of particular relevance to their function. Data from studies made on interactions of electromagnetic fields with the cardiac function have demonstrated that highly interesting changes are present in the heart after exposure to electromagnetic fields. Some electrically sensitive people have symptoms similar to heart attacks after exposure to electromagnetic fields. 
One could speculate that the cardiac mast cells are responsible for these changes due to degranulation after exposure to electromagnetic fields. However, it is still not known how, and through which mechanisms, all these different cells are affected by electromagnetic fields. In this article (Gangi and Johansson, 2000), we present a theoretical model, based upon the above observations of electromagnetic fields and their cellular effects, to explain the proclaimed sensitivity to electric and/or magnetic fields in humans.

In a recent article by Holmboe and Johansson (2005), the functional impairment electrohypersensitivity was investigated with the aim to characterize the complex set of symptoms and to order them according to the WHO's ICQ10 register of diagnoses. Furthermore, we also tested for the presence of increased levels of $\operatorname{IgE}$ or signs of a positive Phadiatop Combi (which is a screening test for allergies towards certain articles of food, pollen, insects, and other animals) which both would be indicators of an immune system alert. If such increases would be found, they could then be used in the diagnosis of electrohypersensitivity.

Twenty-two people ( 5 men, 17 women) participated. The age range was between 25 and 79 years. The symptoms were given in a ranked scale where the symptoms were attributed points according to the following: $0=$ no symptoms at all; $1=$ occasional, mild symptoms; $2=$ occasional, severe symptoms; $3=$ regular, mild symptoms; 4 = regular, severe symptoms.

Symptoms of the skin and the nervous system dominated the picture. The most frequent ones were skin redness, eczema and sweating, loss of memory, concentration difficulties, sleep disturbances, dizziness as well as muscular and joint-related pain, and muscular and joint-related weakness. Headache, faintness, nose blockade, and fatigue were also common. In addition, 19 of the people had symptoms from the gastrointestinal tract. All the people with the impairment electrohypersensitivity had tinnitus.

No connection between IgE blood levels and symptoms could be found, all the people with electrohypersensitivity had normal values $(<122 \mathrm{kU} / 1)$. Only 3 people had a positive Phadiatop Combi.

In summary, it is evident from our preliminary experimental data that various biological alterations are present in the electrohypersensitive persons claiming to suffer from exposure to electromagnetic fields. In view of recent epidemiological studies, pointing to a correlation between long-term exposure from power-frequent magnetic fields or microwaves and cancer, our data ought to be taken seriously and further analyzed.

Thus, it is of paramount importance to continue the investigation of persons with the impairment electrohypersensitivity. We would favor studies of electromagnetic fields' interaction with mast cell release of histamine and other biologically active substances, studies of lymphocyte viability, as well as studies of the newly described serotonin-containing melanocytes. Also, continued analysis of the intraepidermal nerve fibers and their relations to these mast cells and serotonincontaining melanocytes are very important. Finally, not to be forgotten, a general investigation - of persons with the impairment electrohypersensitivity versus normal healthy volunteers-regarding the above markers as well as other markers for cell traffic, proliferation, and inflammation, is very much needed. Such scientific work may lay a firm foundation for necessary adjustment of accessibility, thus helping and supporting all persons with the functional impairment electrohypersensitivity.

In addition to the studies in humans, we have also done a series of animal experiments (Rajkovic et al., 2005a,b, 2006). These have been a collaborative effort 
between the Department of Biology, Faculty of Sciences, Novi Sad, Serbia and Montenegro, and my own research group at the Karolinska Institute, Stockholm, Sweden.

These papers go back to the above-mentioned early observations in people with the impairment electrohypersensitivity where large increases in the cutaneous mast cell count could be demonstrated as compared to normal healthy volunteers. A corresponding effect on cutaneous mast cells from normal healthy volunteers placed in front of ordinary TVs/PCs could also be shown. My working hypothesis since then is that electrohypersensitivity is a kind of irradiation damage, since the observed cellular changes are very much the same as the ones you would find in tissue subjected to UV-light or ionizing radiation (for references, see above).

One very fierce criticism from certain 'opponents' has been that such mast cell alterations in people with electrohypersensitivity (or in normal healthy volunteers) cannot be due to the action of electromagnetic fields (EMFs) and/or airborn chemicals, but must be due to psychological or psychiatric personality disturbances, cognitive malfunction, or likewise.

The aim of these studies has therefore been to investigate the influence of extremely low-frequency electromagnetic fields (ELF-EMFs) on mast cells, parafollicular cells, and nerve fibers in rat skin and thyroid gland, as seen using light and transmission electron microscopy. The experiments were performed on 2month-old Wistar male rats exposed for $4 \mathrm{~h}$ a day, 5 or 7 days a week for 1 month to power-frequent $(50 \mathrm{~Hz})$ EMFs $(100-300 \mu \mathrm{T}, 54-160 \mathrm{~V} / \mathrm{m})$. After sacrifice, samples of skin and thyroid were processed for indirect immunohistochemistry or toluidine blue staining and were then analyzed using the methods of stereology. Antibody markers to serotonin, substance P, calcitonin gene-related peptide (CGRP), and protein gene product 9.5 (PGP) were applied to skin sections and PGP, CGRP, and neuropeptide $Y$ (NPY) markers to the thyroid. A significantly increased number of serotonin-positive mast cells in the skin $(p<0.05)$ and NPY-containing nerve fibers in the thyroid $(p<0.01)$ of rats exposed to ELF-EMF was found compared to controls, indicating a direct EMF effect on skin and thyroid vasculature.

After ultrastructural examination, a predominance of microfollicles with less colloid content and dilated blood capillaries was found in the EMF group. Stereological counting showed a statistically significant increase of the volume density of follicular epithelium, interfollicular tissue, and blood capillaries as well as the thyroid activation index, as compared to the controls. The volume density of colloid significantly decreased. Ultrastructural analysis of thyroid follicular cells in the EMF group revealed the frequent finding of several colloid droplets within the same thyrocyte with the occasional presence of large-diameter droplets. Alterations in lysosomes, granular endoplasmic reticulum, and cell nuclei compared to the control group were also observed. Taken together, the results of this study show the stimulative effect of power-frequency EMFs on thyroid gland at both the light microscopic and the ultrastructural level.

The obtained animal results cannot be understood by psychological or psychiatric theories, but are claimed to be due only to the EMF exposure.

In Sweden, electrohypersensitivity (EHS) is an officially fully recognized functional impairment (i.e., it is not regarded as a disease). Survey studies show that somewhere between 230,000-290,000 Swedish men and women report a variety of symtoms when being in contact with electromagnetic field (EMF) sources.

The electrohypersensitive people have their own handicap organization, The Swedish Association for the ElectroSensitive (http://www.feb.se; the website 
has an English version). This organization is included in the Swedish Disability Federation (Handikappförbundens SamarbetsOrgan; HSO). HSO is the unison voice of the Swedish disability associations towards the government, the parliament, and national authorities, and is a cooperative body that today consists of 43 national disability organizations (where The Swedish Association for the ElectroSensitive is 1 of these 43 organizations) with all together about 500,000 individual members. You can read more on http://www.hso.se (the site has an English short version).

Swedish municipalities, of course, have to follow the UN 22 Standard Rules on the equalization of opportunities for people with disabilities ("Standardregler för att tillförsäkra människor med funktionsnedsättning delaktighet och jämlikhet"; about the UN 22 Standard Rules, see website: http://www.un.org/esa/socdev/enable/dissre00.htm). All people with disabilities shall, thus, be given the assistance and service they have the right to according to the Swedish Act concerning Support and Service for Persons with Certain Functional Impairments (LSS-lagen) and the Swedish Social Services Act (Socialtjänstlagen). People with disabilities, thus, have many different rights and can get different kinds of support. The purpose of those rights and the support is to give every person the chance to live like everyone else. Everyone who lives in the Swedish municipalities should be able to lead a normal life and the municipalities must have correct knowledge and be able to reach the people who need support and service. People with disabilities shall be able to get extra support so that they can live, work, study, or do things they enjoy in their free time. The municipalities are responsible for making sure that everyone gets enough support. Everyone shall show respect and remember that such men and women may need different kinds of support.

In Sweden, impairments are viewed from the point of the environment. No human being is in itself impaired, there are instead shortcomings in the environment that cause the impairment (as the lack of ramps for the person in a wheelchair or rooms electrosanitized for the person with electrohypersensitivity). This environment-related impairment view, furthermore, means that even though one does not have a scientifically based complete explanation for the impairment electrohypersensitivity, and in contrast to disagreements in the scientific society, the person with electrohypersensitivity shall always be met in a respectful way and with all necessary support with the goal to eliminate the impairment. This implies that the person with electrohypersensitivity shall have the opportunity to live and work in an electrosanitized environment.

This view can fully be motivated in relation to the present national and international handicap laws and regulations, including the UN 22 Standard Rules and the Swedish action plan for persons with impairments (prop. 1999/2000:79 "Den nationella handlingplanen för handikappolitiken - Från patient till medborgare"). Also, the Human Rights Act in the EU fully applies.

A person is disabled when the environment contains some sort of impediment. It means that in that moment a man or woman in a wheelchair cannot come onto the bus, a train, or into a restaurant, this person has a disability-he or she is disabled. When the bus, train, or restaurant are adjusted for a wheelchair, the person does not suffer from his disability and is consequently not disabled. An electrohypersensitive person suffers when the environment is not properly adapted according to their personal needs. Strategies to enable a person with this disability to attend common rooms such as libraries, churches, and so on, are, for 
instance to switch off the high-frequency fluorescent lamps and instead use ordinary light bulbs. Another example is the possibility to switch off-the whole or parts ofthe assistive listening systems (persons with electrohypersensitivity are often very sensitive to assistive listening systems).

In the Stockholm municipality-where I live and work as a scientist with the responsibility to investigate comprehensive issues for people with electrohypersensitivity—such persons have the possibility to get their home sanitized for EMFs. This means, for example, that ordinary electricity cables are changed to special cables. Furthermore, the electric stove can be changed to a gas stove and walls, roofs and floors can be covered with special wallpaper or paint with a special shelter to stop EMFs from the outside (from neighbors and mobile telephony base stations). Even the windows can be covered with a thin aluminum foil as an efficient measure to restrain EMFs to get into the room/home. If these alterations turn out not to be optimal they have the possibility to rent small cottages in the countryside that the Stockholm municipality owns. These areas have lower levels of irradiation than others. The Stockholm municipality also intend to build a village with houses that are specially designed for people who are electrohypersensitive. This village will be located in a low-lewel irradiation area. (One of my graduate students, Eva-Rut Lindberg, has in her thesis project studied the "construction of buildings for persons with the impairment electrohypersensitivity". The doctoral thesis will be presented during the spring.)

People with electrohypersensitivity also have a general (legal) right to be supported by their employer so that they can work despite of this impairment. For instance, they can get special equipment such as computers that are of lowemission type, high-frequency fluorescent lamps can be changed to ordinary light bulbs, wireless DECT telephones removed from their rooms, and so on.

Some hospitals in Sweden (e.g., in Umeå, Skellefteå, and Karlskoga) also have built special rooms with very low EMFs so that people who are hypersensitive can get medical care. Another example is the possibility for people who are electrohypersensitive to get a specially designed car so that the person can transport himself/herself between his/her home and their workplace.

Recently, some politicians in the Stockholm municipality even proposed to the politicians responsible for the subway in the Stockholm City that a part of every trainset should be free from mobile phones; that the commuters have to switch of the phones in these selected parts to enable people with electrohypersensitivity to travel with the subway (compare this with people who have an allergy for animal fur whereupon people consequently are prohibited to have animals, such as dogs or cats, in selected parts of the trainset).

In addition, when the impairment electrohypersensitivity is discussed it is also of paramount importance that more general knowledge is needed with the aim to better adapt the society to the specific needs of the persons with this impairment. The Swedish "Miljöbalk" (the Environmental Code) contains an excellent prudence avoidance principle which, of course, must be brought into action also here, together with respect and willingness to listen to the people with electrohypersensitivity.

Naturally, all initiatives for scientific studies of the impairment electrohypersensitivity must be characterized and marked by this respect and willingness to listen, and the investigations shall have the sole aim to help the persons with this particular impairment. Rule 13 in the UN 22 Standard Rules clearly says that scientific investigations of impairments shall, in an unbiased way-and without any 
prejudice-focus on cause, occurrence and nature and with the sole and explicit purpose to help and support the person with the impairment. Nothing else!

In addition, it must also be mentioned that quite recently, by the end of 2004, The Irish Doctors' Environmental Association (IDEA) has announced that "they have identified a sub-group of the population who are particularly sensitive to exposure to different types of electromagnetic radiation. The safe levels currently advised for exposure to this non-ionising radiation are based solely on its thermal effects. However, it is clear that this radiation also has non-thermal effects, which need to be taken into consideration when setting these safe levels. The electrosensitivity experienced by some people results in a variety of distressing symptoms which must also be taken into account when setting safe levels for exposure to non-ionising radiation and when planning the siting of masts and transmitters" (IDEA, 2004).

Furthermore, the IDEA also points out the following:

1. An increasing number of people in Ireland are complaining of symptoms which, while they may vary in nature, intensity, and duration, can be demonstrated to be clearly related to exposure to electro-magnetic radiation (EMR).

2. International studies on animals over the last 30 years have shown the potentially harmful effects of exposure to electro-magnetic radiation. In observational studies, animals have shown consistent distress when exposed to EMR. Experiments on tissue cultures and rats have shown an increase in malignancies when exposed to mobile telephone radiation.

3. Studies on mobile telephone users have shown significant levels of discomfort in certain individuals following extensive use or even, in some cases, following regular short-term use.

4. The current safe levels for exposure to microwave radiation were determined based solely on the thermal effects of this radiation. There is now a large body of evidence that clearly shows that this is not appropriate, as many of the effects of this type of radiation are not related to these thermal effects (IDEA, 2004).

Finally, The IDEA "believes that the Irish Government should urgently review the information currently available internationally on the topic of the thermal and non-thermal effects of exposure to electro-magnetic radiation with a view to immediately initiating appropriate research into the adverse health effects of exposure to all forms of non-ionising radiation in this country, and into the forms of treatment available elsewhere. Before the results of this research are available, an epidemiological database should be initiated of individuals suffering from symptoms thought to be related to exposure to non-ionising radiation. Those claiming to be suffering from the effects of exposure to electro-magnetic radiation should have their claims investigated in a sensitive and thorough way, and appropriate treatment provided by the State. The strictest possible safety regulations should be established for the installation of masts and transmitters, and for the acceptable levels of potential exposure of individuals to electro-magnetic radiation, in line with the standards observed in New Zealand." (IDEA, 2004). Of course, these very recent findings must also be taken into serious consideration for any research proposal. 
It may also be noted that a unique conference recently was held in Stockholm in May, 2006. The theme for the conference was "The right for persons with the impairment electrohypersensitivity to live in a fully accessible society". The conference was organized by the Stockholm City municipality and the Stockholm County Council and dealt with the most recent measures to make Stockholm fully accessible for persons with the impairment electrohypersensitivity. Among such measures are to offer home equipment adjustments and ban mobile phones from certain underground cars as well as certain public bus seats, and through electrosanitized hospital wards. The conference was documented on film.

The effects of various forms of electromagnetic fields are also discussed within areas of medicine, such as cancer. Cancer is, unfortunately, spreading in the modern society. Nearly all cancer forms are increasing when it comes to incidence, i.e., new cases/year (cf. Hallberg and Johansson, 2002a). It could recently be read in the BBC News that skin cancer is rising in young adults, and Sara Hiom, head of the health information at Cancer Research UK said, when interviewed, that "Non-melanoma cancers are rising at an alarming rate".

More and more research efforts goes into understanding the molecular mechanisms behind these various progressive cancer forms, and much more money is spent on finding new drugs to treat patients. However, oddly enough, very little is spent on understanding the actual causes for cancer. Among such possible causative agents, more and more focus is nowadays put on modern gadgets, such as mobile telephones and computers, and their chemical and physical emissions, including flame retardants and electromagnetic non-ionizing radiation.

Childhood leukemia was early connected to power-frequent magnetic fields already in the pioneering work by Wertheimer and Leeper (1979), and more recently, Scandinavian scientists have identified an increased risk for acoustic neuroma (i.e., a benign tumor of the eighth cranial nerve) in cell phone users, as well as a slightly increased risk of malignant brain tumors such as astrocytoma and meningioma on the same side of the brain as the cell phone was habitually held (Hardell et al., 1999, 2004, 2005; Lonn et al., 2004). In addition, a clear association between adult cancers and FM radio broadcasting radiation has been noticed, both in time and location (Hallberg and Johansson, 2002b, 2004a, 2005a). Initial studies on facial nevi indicates that nowadays young children also can have a substantial amount of these. If it can be shown that radiofrequent radiation is not correlated with child cancers, the current focus on low-frequency electromagnetic fields can continue. If there is also a radiofrequent and/or microwave correlation, then this must be considered in future research as well as in today's preventive work.

Most recently, Dr. Djemal Beniashvili and other scientists at the Edith Wolfson Medical Center in Holon, Israel, have demonstrated a possible link between exposure to power-frequent electromagnetic fields and breast cancer in elderly women (Beniashvili et al., 2005). They compared the breast cancer rates in elderly women from an earlier period (1978-1990) to a more recent period (1991-2003), which has been characterized by a much more extensive use of personal computers (more than three hours a day), mobile telephones, TV sets, and other household electrical appliances. They used available medical records extending over a period of 26 years, involving the analysis of more than 200,000 samples.

Among the elderly women who developed breast cancer in the first time frame, $20 \%$ were regularly exposed to power-frequent fields. But in the more modern period, $51 \%$ were so exposed, mainly through the use of personal 
computers. The authors concluded: "There was a statistically significant influence of electromagnetic fields on the formation of all observed epithelial mammary tumours in the second group." This represented a more than two-fold increase, which was considered highly significant (cf. Beniashvili et al., 2005).

Of course, many other environmental factors have changed during the period 1978-1990, but increased environmental exposure to power-frequent fields is among the more conspicuous changes to have taken place. Naturally, there are many aspects of this question that remain to be clarified, and, from a scientific point of view, it is far from conclusively settled.

During the second half of the 20th century an increasing rate of lung cancer was noticed in Sweden. Since the mid-1960's, tobacco smoking has been associated with this cancer and believed to be the main cause. Less noticed, though, is the fact that no connection between smoking and lung cancer was noticed before 1955. Together with my co-worker Örjan Hallberg, we have therefore initiated a project with the intention to review facts that may shed new light on this sudden increase in getting lung cancer after 1955 in Sweden.

A large number of scientific reports point at tobacco smoking as being the main cause of the increasing rate of lung cancer in the world. These reports have mainly been produced during the second half of the 20th century. The Swedish National Board of Health and Welfare ("Socialstyrelsen") states that $80-90 \%$ of the lung cancer deaths are caused by smoking. The main part of the victims are also smokers. About $10 \%$ of the lung cancer deaths have been non-smokers. This has led to the suspicion that also passive smoking can cause lung cancer. Other environmental factors such as radon and asbestos are believed to cause a number of lung cancer deaths per year, and especially if combined with smoking.

As pointed out above, Hallberg and Johansson have earlier reported about a strong association between body-resonant non-ionizing radiation (FM-radio, $100 \mathrm{MHz}$ ) and the existence of malignant melanoma of the skin (Hallberg and Johansson, 2002b, 2004a, 2005a). Since this frequency range has a penetration depth of about $10 \mathrm{~cm}$ into the human body, there is a suspicion that resonant currents may affect the immune defense system also when it comes to beating cancer cells in the lungs. Due to that it is well motivated to study in detail how the presence and rate of lung cancer have changed in Sweden, and in other countries, as this new environmental factor was added.

In a yet unpublished report (Hallberg and Johansson, 2006), we have shown how the rate of lung cancer can accelerate in connection with a sudden exposure of a population to such body-resonant radiation. From this work, it can be noticed that people who have been smoking for many years suddenly could get lung cancer relatively short after the introduction of the FM-radio. This abrupt increase was not noticed in counties where the FM-radio still was not rolled out. It is also noticeable that deaths due to asbestosis have not been known until after the 1960's despite the fact that asbestos has been used as a building material since the end of the 19th century. In our work it is also shown how weak the connection is between lung cancer and cigarette consumption in a number of countries. But if the lung cancer mortality is normalized to the melanoma of skin mortality in the same countries, all of a sudden a very strong correlation appears. This indicates that there is a common factor behind the fast increasing mortality of skin and lung cancer that we have noticed, e.g., in Sweden.

An automated computer analysis of the age-specific incidence of lung cancer among men in Sweden points at year 1955 as the starting year for a sudden 
environmental change in Sweden and that this disturbance mainly affects men over 60 years of age. This method of analysis has successfully been applied to study the development of melanoma of skin in Sweden, Norway, Denmark, Finland, and the U.S.

Authorities responsible for the health of the general population should have a big interest in causative factors behind such major cancer types. Doctors and specialists should know more about the real causes behind lung cancer. Epidemiologists in general might get inspired to test new methods and to look at population health problems from a new perspective. Only the future, however, will know the answer to these medical hypotheses.

Finally, as already mentioned, one issue that is very much addressed in the public as well as in the scientific literature is the question about the effect(s) of mobile phone radiation on health. Ten years of intensively increasing mobile phone usage have passed. According to some, it has facilitated our lifestyle, but more and more people are nowadays concerned about the lack of knowledge regarding the effects of radiation on health. For instance, it may be noted that mobile and DECT telephones are among the worst sources of problems for electrohypersensitive persons. In addition, it is now a well-known and fully accepted fact that mobile phone usage causes injuries in traffic and during work.

Mobile telephony-related risks may be divided between effects of radiation (microwaves, low-frequency magnetic fields) from the hand-held mobile telephone and radiation (microwaves) from remote base stations mounted on roofs, walls, towers, masts, etc.

Extensive laboratory research on animals, mainly rats, has not revealed premature death, increased cancer risk, or general sickness. However, very little can be drawn from this since rats and other laboratory animals have a maximal life span of approximately two years. The human cancer data point, instead, on an exposure time needed of at least five years, thus data from rats will not be of any real use. In addition, other biologic or metabolic parameters, as well as molecular biology and genetic data, are missing.

Epidemiological research with human case-control methodology suggests an increased risk for highly malignant brain lesions and acoustic neuromas after extended use (>5 years; Hardell et al., 1999, 2004, 2005; Lonn et al., 2004), but additional confirmation is needed. The present epidemiological surveillance thus indicates an increased risk for cancer in humans but observation times are too short. Ecological studies, in addition, suggest an increased general health degradation in areas of high average output power from the hand-held mobile phones (Hallberg and Johansson, 2004b,c,d, 2005b).

There is still insufficient contemporary proof with regard to increased cancer risk to change adult mobile phone usage. However, signs of degrading general health in sparsely populated areas suggest that the use of mobile phones at high output power levels should be avoided. Therefore, it is now of paramount importance that epidemiological research should be supplemented with prospective studies and quality exposure data (standardization). Continuous surveillance is also needed. In the meantime, children and adolescents should definitely be discouraged to use mobile phones.

It is a must that fully financied, truly independent research projects immediately should be initiated to ascertain the public health. They shall be completely devoid of commercial interests of any sort. This is the responsibility of each elected 
government in each country, and is of special importance for people with the functional impairment electrohypersensitivity.

\section{Acknowledgments}

Supported by the Karolinska Institute, the Cancer and Allergy Foundation (Canceroch Allergifonden), Sif, and TCO Developments.

\section{References}

Beniashvili, D., Avinoach'm, I., Baasov, D., Zusman, I. (2005). The role of household electromagnetic fields in the development of mammary tumors in women: clinical caserecord observations. Med. Sci. Monit. 11:CR10-13.

Fews, A. P., Henshaw, D. L., Keitch, P. A., Close, J. J., Wilding, R. J. (1999a). Increased exposure to pollutant aerosols under high voltage power lines. Int. J. Radiat. Biol. 75:1505-1521.

Fews, A. P., Henshaw, D. L., Wilding, R. J., Keitch, P. A. (1999b). Corona ions from powerlines and increased exposure to pollutant aerosols. Int. J. Radiat. Biol. 75:1523-1531.

Gangi, S., Johansson, O. (1997). Skin changes in "screen dermatitis" versus classical UV- and ionizing irradiation-related damage-similarities and differences. Two neuroscientists' speculative review. Exp. Dermatol. 6:283-291.

Gangi, S., Johansson, O. (2000). A theoretical model based upon mast cells and histamine to explain the recently proclaimed sensitivity to electric and/or magnetic fields in humans. Med. Hypotheses 54:663-671.

Hallberg, Ö., Johansson, O. (2002a). Cancer trends during the 20th century. J. Aust. Coll. Nutr. Env. Med. 21:3-8.

Hallberg, Ö., Johansson, O. (2002b). Melanoma incidence and frequency modulation (FM) broadcasting. Arch. Environ. Health 57:32-40.

Hallberg, Ö., Johansson, O. (2004a). Malignant melanoma of the skin—not a sunshine story! Med. Sci. Monit. 10:CR336-340.

Hallberg, Ö., Johansson, O. (2004b). 1997-A curious year in Sweden. Eur. J. Cancer Prev. 13:535-538.

Hallberg, Ö., Johansson, O. (2004c). Long-term sickness and mobile phone use. J. Aust. Coll. Nutr. Env. Med. 23:11-12.

Hallberg, Ö., Johansson, O. (2004d). Mobile handset output power and health. Electromag. Biol. Med. 23:229-239.

Hallberg, Ö., Johansson, O. (2005a). FM broadcasting exposure time and malignant melanoma incidence. Electromag. Biol. Med. 24:1-8.

Hallberg, Ö., Johansson, O. (2005b). Alzheimer mortality-why does it increase so fast in sparsely populated areas? Eur. Biol. Bioelectromag. 1:225-246.

Hallberg, Ö., Johansson, O. (2006). Lung cancer may accelerate during exposure to bodyresonant FM-broadcasting radiation. To be submitted.

Hardell, L., Näsman, Å., Påhlson, A., Hallquist, A., Hansson Mild, K. (1999). Use of cellular telephones and the risk for brain tumours: a case-control study. Int. J. Oncol. 15:113-116.

Hardell, L., Mild, K. H., Carlberg, M., Hallquist, A. (2004). Cellular and cordless telephone use and the association with brain tumors in different age groups. Arch. Environ. Health 59:132-137.

Hardell, L., Carlberg, M., Mild, K. H. (2005). Case-control study on cellular and cordless telephones and the risk for acoustic neuroma or meningioma in patients diagnosed 2000-2003. Neuroepidemiology 25:120-128. 
Hilliges, M., Wang, L., Johansson, O. (1995). Ultrastructural evidence for nerve fibers within all vital layers of the human epidermis. J. Invest. Dermatol. 104:134-137.

Holmboe, G., Johansson, O. (2005). Symptombeskrivning samt förekomst av IgE och positiv Phadiatop Combi hos personer med funktionsnedsättningen elöverkänslighet, (= Description of symptoms as well as occurrence of IgE and positive Phadiatop Combi in persons with the physical impairment electrohypersensitivity, in Swedish). Medicinsk Access 1:58-63.

IDEA, The Irish Doctors' Environmental Association (2004). IDEA position on electromagnetic radiation. http://www.ideaireland.org/emr.htm.

Johansson, O., Liu, P.-Y. (1995). "Electrosensitivity", "electrosupersensitivity" and "screen dermatitis": preliminary observations from on-going studies in the human skin. In: Simunic, D., ed. Proceedings of the COST 244: Biomedical Effects of Electromagnetic Fields - Workshop on Electromagnetic Hypersensitivity. Brussels/Graz: EU/EC (DG XIII), pp. 52-57.

Johansson, O., Hilliges, M., Björnhagen, V., Hall, K. (1994). Skin changes in patients claiming to suffer from "screen dermatitis": a two-case open-field provocation study. Exp. Dermatol. 3:234-238.

Johansson, O., Hilliges, M., Han, S. W. (1996). A screening of skin changes, with special emphasis on neurochemical marker antibody evaluation, in patients claiming to suffer from screen dermatitis as compared to normal healthy controls. Exp. Dermatol. 5:279-285.

Johansson, O., Wang, L., Hilliges, M., Liang, Y. (1999). Intraepidermal nerves in human skin: PGP 9.5 immunohistochemistry with special reference to the nerve density in skin from different body regions. J. Peripher. Nerv. Syst. 4:43-52.

Johansson, O., Gangi, S., Liang, Y., Yoshimura, K., Jing, C., Liu, P.-Y. (2001). Cutaneous mast cells are altered in normal healthy volunteers sitting in front of ordinary TVs/PCsresults from open-field provocation experiments. J. Cutan. Pathol. 28:513-519.

Lonn, S., Ahlbom, A., Hall, P., Feychting, M. (2004). Mobile phone use and the risk of acoustic neuroma. Epidemiology 15:653-659.

Nordström, G. (2004). The Invisible Disease-The Dangers of Environmental Illnesses caused by Electromagnetic Fields and Chemical Emissions. Hants and New York: O Books.

Rajkovic, V., Matavulj, M., Johansson, O. (2005a). Histological characteristics of cutaneous and thyroid mast cell populations in male rats exposed to power-frequency electromagnetic fields. Int. J. Radiat. Biol. 81:491-499.

Rajkovic, V., Matavulj, M., Johansson, O. (2005b). The effect of extremely low-frequency electromagnetic fields on skin and thyroid amine- and peptide-containing cells in rats: an immunohistochemical and morphometrical study. Environ. Res. 99:369-377.

Rajkovic, V., Matavulj, M., Johansson, O. (2006). Light and electron microscopic study of the thyroid gland in rats exposed to power-frequency electromagnetic fields. J. Exp. Biol. 209:3322-3328.

Swedish Association for the Electrosensitive. http://www.feb.se

Swedish Disability Foundation. http://hso.se

United Nations General Assembly. (1993). The standard rules on the equalization of opportunities for persons with disabilities. http://www/un.org/esa/socdev/ enable/dissre00.htm

Wang, L., Hilliges, M., Jernberg, T., Wiegleb-Edstrom, D., Johansson, O. (1990). Protein gene product 9.5-immunoreactive nerve fibres and cells in human skin. Cell Tissue Res. 261:25-33.

Wertheimer, N., Leeper, E. (1979). Electrical wiring configurations and childhood cancer. Am. J. Epidemiol. 109:273-284.

Yoshimura, K., Liang, Y., Kobayashi, K., Johansson, O. (2006). Alteration of the Merkel cell number in the facial skin of electrosensitive persons-a morphological study. To be submitted. 